\title{
A Hydrothermal After-Ripening Time Model for Seed Dormancy Loss in Bromus Tectorum L.
}

Phil S. Allen

Phil_Allen@byu.edu

Necia B. Bair

Follow this and additional works at: https://scholarsarchive.byu.edu/facpub

Part of the Biology Commons

\section{Original Publication Citation}

Seed Science Research 16.1(Mar 26): 17-28.

\section{BYU ScholarsArchive Citation}

Allen, Phil S. and Bair, Necia B., "A Hydrothermal After-Ripening Time Model for Seed Dormancy Loss in Bromus Tectorum L." (2006). Faculty Publications. 322.

https://scholarsarchive.byu.edu/facpub/322 


\title{
A hydrothermal after-ripening time model for seed dormancy loss in Bromus tectorum L.
}

\author{
Necia B. Bair ${ }^{1}$, Susan E. Meyer ${ }^{2}$ and Phil S. Allen ${ }^{1 *}$ \\ ${ }^{1}$ Department of Plant and Animal Sciences, Brigham Young University, Provo, UT 84602, USA; ${ }^{2}$ USDA Forest \\ Service, Rocky Mountain Research Station, Shrub Sciences Laboratory, Provo, UT 84606, USA
}

\begin{abstract}
After-ripening, the loss of dormancy under dry conditions, is associated with a decrease in mean base water potential for germination of Bromus tectorum L. seeds. After-ripening rate is a linear function of temperature above a base temperature, so that dormancy loss can be quantified using a thermal after-ripening time (TAR) model. To incorporate storage water potential into TAR, we created a hydrothermal after-ripening time (HTAR) model. Seeds from two $B$. tectorum populations were stored under controlled temperatures $\left(20\right.$ or $\left.30^{\circ} \mathrm{C}\right)$ and water potentials $(-400$ to $-40 \mathrm{MPa})$. Subsamples were periodically removed from each storage treatment and incubated at 15 or $25^{\circ} \mathrm{C}$ to determine germination time courses. Dormancy status (mean base water potential) was calculated from each time course using hydrothermal time equations developed for each seed collection. Seeds stored at $-400 \mathrm{MPa}$ did not afterripen. At water potentials from -400 to $-150 \mathrm{MPa}$, the rate of after-ripening increased approximately linearly with increasing water potential. Between -150 and $-80 \mathrm{MPa}$, there was no further increase in afterripening rate, while at $-40 \mathrm{MPa}$ seeds did not afterripen and showed loss of vigour. These results suggest that the concept of critical water potential thresholds, previously shown to be associated with metabolic activity and desiccation damage in partially hydrated seeds, is also relevant to the process of afterripening. The HTAR model generally improved field predictions of dormancy loss when the soil was very dry. Reduced after-ripening rate under such conditions provides an ecologically relevant explanation of how seeds prolong dormancy at high summer soil temperatures.
\end{abstract}

*Correspondence:

Fax: +1 8014220008

Email: phil_allen@byu.edu
Keywords: after-ripening, Bromus tectorum, dormancy loss, hydrothermal after-ripening time, hydrothermal time, modelling, water potential

\section{Introduction}

Seed germination is strongly influenced by temperature and water potential, and can be described by models based on hydrothermal time. Hydrothermal concepts underlie many recent efforts to predict seed germination, as well as dormancy loss (reviewed by Allen, 2003; Bradford, 2005). Hydrothermal time was first proposed by Gummerson (1986) and further developed by Bradford (1990, 1995). The hydrothermal time equation for a given germination fraction is:

$$
\theta_{\mathrm{HT}}=\left(\Psi-\Psi_{\mathrm{b}}(g)\right)\left(T-T_{\mathrm{b}}\right) t_{g}
$$

where $\theta_{\mathrm{HT}}$ is the amount of hydrothermal time (i.e. $\mathrm{MPa}^{\circ} \mathrm{d}$ ) required for germination to occur, $\Psi$ is the water potential of the incubation medium, $\Psi_{b}(g)$ is the base water potential below which germination will not occur for fraction $g, T$ is the incubation temperature, $T_{\mathrm{b}}$ is the base (minimum) temperature for germination, and $t_{g}$ is the actual time to germination for fraction $g$. In order to extend equation (1) to describe germination for a seed population, Gummerson (1986) assumed that the distribution of mean base water potentials within a population was normal. Probit transformation, which linearizes a cumulative normal distribution curve, could then be incorporated to predict germination for all seed fractions, as follows:

$\operatorname{Probit}\left(g / g_{\mathrm{m}}\right)=\left[\Psi-\Psi_{\mathrm{b}}(50)-\theta_{\mathrm{HT}} /\left(\left(T-T_{\mathrm{b}}\right) t_{g}\right)\right] / \sigma_{\Psi \mathrm{b}}$

where $g_{\mathrm{m}}$ is the fraction of viable seeds in the population, $\Psi_{\mathrm{b}}(50)$ is the mean (median) base water potential of the population, and $\sigma_{\psi b}$ is the standard deviation of base water potentials within the population.

While the assumptions underlying hydrothermal time have been questioned (Phelps and Finch-Savage, 1997; Hardegree et al., 1999; Kebreab and Murdoch, 
1999), hydrothermal models do provide a quantitative description of seed germination rates based on actual $\Psi$ and $T$ conditions. Modelling efforts based on hydrothermal time have provided many insights into germination-related phenomena, and serve as a useful tool in predicting germination outcomes (Bradford, 2002). For example, treatments that cause an upward shift in $\Psi_{\mathrm{b}}(50)$ lead to a decreased germination rate and, if sufficient, a decrease in germination percentage as well (Bradford, 1990, 1995; Christensen, et al., 1996). Similarly, germination rate and percentage at a given incubation water potential are increased by more negative $\Psi_{b}(50)$ values. Shifts in $\Psi_{b}(50)$ above the water potential of the imbibition medium can explain germination behaviours such as dormancy cycling (Bradford, 2002), as well as the delay and inhibition of seed germination in the supra-optimal temperature range (Bauer et al., 1998; Shrestha et al., 1999; Meyer et al., 2000; Alvarado and Bradford, 2002; Rowse and Finch-Savage, 2003).

The discovery that after-ripening rate is a linear function of storage temperature above a specific base temperature led to the use of thermal time to describe rates of dormancy loss in Bromus tectorum seeds (Christensen et al., 1996), a winter annual that has invaded a wide variety of habitats in western North America (Mack, 1981). In order to predict dormancy loss in the field, Bauer et al. (1998) used the hydrothermal time parameter mean base water potential $\left[\Psi_{\mathrm{b}}(50)\right]$ as an index of dormancy status. Thermal after-ripening time (TAR) models successfully predicted dormancy loss in dry soil for B. tectorum seeds in the field as long as mean daily soil water potential remained above $-150 \mathrm{MPa}$.

In earlier studies using seeds of wild oat (Avena fatua; Foley, 1994) and red rice (Oryza sativa L.; Leopold et al., 1988), after-ripening was slowed or prevented at very low seed water contents. Citing unpublished data, Leopold and Vertucci (1989) reported that afterripening of red rice seeds did not occur at water contents below $0.05 \mathrm{~g} \mathrm{H}_{2} \mathrm{O}$ ( $\mathrm{g}$ dry weight) ${ }^{-1}$ and was also retarded at water contents above $0.15 \mathrm{~g} \mathrm{H}_{2} \mathrm{O} \mathrm{g}^{-1}$. Walters et al. (2001) suggested that specific reactions associated with water content thresholds in partially hydrated seeds could apply to a variety of developmental processes. For example, below c. $-150 \mathrm{MPa}$, enzyme-mediated catabolic activities in seeds are restricted, while certain reactions leading to free radical production are increased (Leopold and Vertucci, 1989; Vertucci and Farrant, 1995).

The objectives of the present study were: (1) to determine how storage at low water potentials affects after-ripening rate for $B$. tectorum seeds; (2) to expand the TAR model to account for seed water potential, i.e. to develop a hydrothermal after-ripening time (HTAR) model to describe seed dormancy loss; and (3) to create and test a field simulation model using
HTAR concepts and measured values for soil water potential and temperature to predict dormancy loss under very dry seed-zone conditions.

The research was carried out in two phases. In the first phase we performed preliminary laboratory experiments on the effect of storage water potential on after-ripening. We used this provisional data set to construct a simulation model for dormancy loss in field seed zones with widely fluctuating water potentials, and tested this model with data from a field seed retrieval experiment. In the second phase, we conducted much more detailed laboratory experiments on the effect of water potential on dormancy loss, and developed a conceptual model to describe dormancy loss rates as a function of water potential over the range -400 to $-40 \mathrm{MPa}$.

\section{Materials and methods}

\section{Laboratory experiment - 1994}

Mature florets (hereafter referred to as seeds) of B. tectorum were collected from two semi-arid Great Basin sites (Whiterocks, Utah, a salt desert shrub site, and Hobblecreek Canyon, Utah, a mountain brush site) in June 1994. Seeds were air-dried to a water content of $0.08-0.10 \mathrm{~g} \mathrm{H}_{2} \mathrm{O}$ ( $\mathrm{g}$ dry weight $)^{-1}$, cleaned by rubbing and fanning, and hand-examined to ensure fill.

Seeds were stored at factorial combinations of temperature $\left(20\right.$ or $\left.30^{\circ} \mathrm{C}\right)$ and water potential $(-300$, -150 or $-80 \mathrm{MPa})$. Storage water potentials were obtained by equilibrating seeds above saturated salt solutions ( $\mathrm{LiCl}, \mathrm{MgCl}_{2}$ and $\mathrm{CaNO}_{3}$, respectively) in sealed containers (Winston and Bates, 1960; Schneider and Schneider, 1972). Subsamples of seeds were removed for evaluation of dormancy status at intervals from 0 to 14 weeks. Four replications of 25 seeds were used for each incubation treatment. Seeds were placed in $100 \times 15 \mathrm{~mm}$ Petri dishes on two layers of blue blotter paper (Anchor Paper, St. Paul, Minnesota, USA) saturated with water and incubated at each of two alternating temperature regimes (10/ $20^{\circ} \mathrm{C}$ and $20 / 30^{\circ} \mathrm{C}, 12 \mathrm{~h}: 12 \mathrm{~h}$, with cool white fluorescent light during the warmer part of the temperature cycle). Dishes were stacked in clear plastic bags, with a water-saturated paper towel placed at the bottom of each bag to reduce evaporative loss. Germinated seeds (radicle emergence $\geq 1 \mathrm{~mm}$ ) were counted and removed on days $1,2,4,7,11,14,21$ and 28.Viability of the remaining ungerminated seeds was then determined using a cut test (e.g. Meyer et al., 2000).

\section{Field after-ripening experiment - 1994}

A field retrieval study using the 1994 seed collections from Whiterocks and Hobblecreek was conducted, 
starting within a week of seed harvest in June 1994 at Point of the Mountain, Utah, a sagebrush/grass site with sandy loam soil. Seeds were air-dried, placed inside nylon mesh bags and buried approximately $5 \mathrm{~mm}$ below the soil surface. Each bag contained approximately 200 seeds, as estimated by weighing. The bags were placed in four rows of 25 bags each, and four bags of each collection (one bag per row) were retrieved weekly from the experimental site. Seeds were transported from the field to the laboratory (about 30 min transit time) in plastic bags to minimize changes in water content. There was no precipitation and, consequently, no germination during the first 7 weeks of the retrieval experiment, the period over which we tracked dormancy loss in the field. The after-ripening portion of the field retrieval experiment was completed with the first major rains of late summer.

Seeds in each bag were divided into two approximately equal groups. The first group of seeds was incubated at $10 / 20^{\circ} \mathrm{C}$ and the second at $20 / 30^{\circ} \mathrm{C}$ (12 h:12 h with fluorescent light during the warm part of the cycle; hereafter reported as 15 and $25^{\circ} \mathrm{C}$ ). Germination time courses were obtained as described previously. Temperature and water potential of the seed zone (approximately the top $1 \mathrm{~cm}$ of soil) at the field site were measured using thermistor (Omnidata, Logan, Utah, USA) and Aquatel sensors (Automata Inc., Grass Valley, California, USA), respectively. Measurements were recorded hourly, as an average of six 10-min readings, using a data logger (Omnidata Easylogger 900, Logan, Utah, USA). Aquatel sensors measure capacitance of the soil, which varies as a function of water content and soil characteristics. Laboratory calibrations were performed to determine water content values corresponding to soil capacitance readings. Corresponding water potential values were determined using a soil water release curve for this soil (Hanks, 1992).

A second method used to predict water potential in the field involved estimating seed-zone water potential, based upon measured temperature at the soil surface, as well as temperature and relative humidity at $1 \mathrm{~m}$ above the surface, and then solving for soil water potential according to the following equation:

$$
\Psi_{\mathrm{a}}=(\mathrm{RT} / V \mathrm{~m})\left(\ln \mathrm{e} / \mathrm{e}^{\circ}\right)
$$

where $\Psi_{\mathrm{a}}$ is the atmospheric water potential (in megapascals, $\mathrm{MPa}$ ), $\mathrm{R}$ is the gas constant $\left(8.2 \mathrm{MPa} \mathrm{cm}^{3} \mathrm{molK}\right), T$ is the temperature of the soil in degrees Kelvin, $V \mathrm{~m}$ is the molar volume of water $\left(18 \mathrm{~cm}^{3} \mathrm{~mol}\right)$, and $\ln \mathrm{e} / \mathrm{e}^{\circ}$ is the natural logarithm for actual water vapour pressure divided by the saturating vapour pressure for that temperature $\left(\ln \mathrm{e} / \mathrm{e}^{\circ} \times 100=\right.$ relative humidity). This method assumes that the water vapour in the air and soil are the same, an assumption that is valid only in soils dry enough for the water content below the seed zone to be negligible (i.e. there is no significant movement of water vapour to the seed zone from greater soil depths).

\section{Laboratory experiment - 2002}

Mature seeds of B. tectorum were hand-collected from Whiterocks and Hobblecreek Utah in June of 2002 and cleaned as described previously. Seeds were stored at factorial combinations of temperature $\left(20\right.$ or $\left.30^{\circ} \mathrm{C}\right)$ and water potential $(-400,-350,-300,-200,-150,-80$ or $-40 \mathrm{MPa}$ ) in the dark. Storage water potentials were obtained by equilibrating seeds above saturated salt solutions [ $\mathrm{ZnCl}_{2}, \mathrm{KOH}, \mathrm{LiCl}$, (glycerol, see below), $\mathrm{MgCl}_{2}, \mathrm{CaNO}_{3}$, and $\mathrm{NaCl}$, respectively; Winston and Bates, 1960; Schneider and Schneider, 1972] or glycerol solutions ( -200 and $-150 \mathrm{MPa}$; Forney and Brandl, 1992). A - $200 \mathrm{MPa}$ glycerol solution was used because the appropriate saturated salt solution proved unstable, and a $-150 \mathrm{MPa}$ glycerol solution was included to verify that glycerol and salt solutions produced similar results. Water potential over each salt solution varied slightly as a function of storage temperature; mean values were used for data analysis and presentation, except for the seed water content data. Seed water content was determined gravimetrically for subsamples of seeds equilibrated for 8 weeks at each storage temperature-water potential combination, as described by Copeland and McDonald (2001).

For evaluation of dormancy status, seeds were removed from storage at intervals ranging from 0 to 73 weeks and placed in 15 and $25^{\circ} \mathrm{C}$ incubation treatments in water, as described previously, except that seeds were incubated in the dark, with fluorescent light only during germination scoring. The use of constant temperature regimes for 2002 (i.e. 15 and $25^{\circ} \mathrm{C}$ incubation, instead of alternating $10 / 20$ and $20 / 30^{\circ} \mathrm{C}$ ) facilitated germinating seeds at several different water potentials throughout after-ripening, which would not have been practical with alternating temperature regimes. The timing of seed transfer from storage to incubation was based on how rapidly seeds lost dormancy. Seeds were stored at the lowest water potentials for up to 73 weeks, while seeds at less negative water potentials were stored for as little as 18 weeks. Germination time-course data were obtained for each treatment combination, as described previously.

\section{Data analysis}

In order to determine hydrothermal time parameters for each seed collection in both 1994 and 2002, fully after-ripened seeds were incubated at two temperatures $\left(15\right.$ and $\left.25^{\circ} \mathrm{C}\right)$ at each of four water potentials $(0,-0.5,-1.0$ and $-1.5 \mathrm{MPa})$. Blotters were 
saturated with water or solutions of polyethylene glycol (PEG) 8000 at the desired water potential. PEG was mixed according to Michel (1983). Germination time courses obtained, as described above, from all incubation water potential and temperature combinations for each seed collection were combined for analysis using repeated probit regression. The hydrothermal time analysis consisted of regressing probit $(g)$ on $\Psi_{\mathrm{b}}(g)$, calculated as $\left[\Psi-\theta_{\mathrm{HT}} /((T-\right.$ $\left.\left.T_{\mathrm{b}}\right) t_{g}\right)$ ] (Bauer et al., 1998), adjusting the value of $\theta_{\mathrm{HT}}$ until the highest $R^{2}$ value for the regression was obtained. From the regression line with the best fit, probit $\left(g / g_{\mathrm{m}}\right)=m\left(\Psi_{\mathrm{b}}(g)\right)+b$, mean base water potential $\left(\Psi_{\mathrm{b}}(50)\right)$ and standard deviation for base water potentials $\left(\sigma_{\Psi \mathrm{b}}\right)$ were determined according to the following relationships: $\Psi_{\mathrm{b}}(50)=-b / m$ and $\sigma_{\Psi \mathrm{b}}=$ $1 / m$ (Christensen et al., 1996).

Next, $\Psi_{\mathrm{b}}(50)$ values were calculated from the germination time courses for seeds stored at each temperature-water potential-storage duration-incubation temperature combination. Once the hydrothermal parameters $\theta_{\mathrm{HT}}$ and $\sigma_{\Psi \mathrm{b}}$ had been determined for a seed collection, the $\Psi_{\mathrm{b}}(50)$ characterizing each germination curve could be calculated from the relationship:

$$
\Psi_{\mathrm{b}}(50)=-\theta_{\mathrm{HT}} /\left(T\left(t_{50}\right)\right) .
$$

This equation can be derived from equation (1) by defining $T_{\mathrm{b}}=0^{\circ} \mathrm{C}$ (the base temperature for germination in this species; Christensen et al., 1996) and $\Psi=$ $0 \mathrm{MPa}$. Estimation of $\Psi_{\mathrm{b}}(50)$ for highly dormant seed samples (i.e. final germination $<50 \%$ ) is described in detail in Bauer et al. (1998). These calculated $\Psi_{\mathrm{b}}(50)$ values served as measures of the dormancy status of seed subsamples after storage for given intervals at each water potential-temperature combination and incubation at each temperature.

Characterizing decreases in $\Psi_{b}(50)$ (i.e. dormancy loss) through time at two storage temperatures makes it possible to determine the thermal time required for after-ripening. The TAR equation is:

$$
\theta_{\mathrm{AT}}=\left(T_{\mathrm{s}}-T_{1}\right) t_{\mathrm{ar}}
$$

where $\theta_{\mathrm{AT}}$ is the thermal time required for afterripening, $T_{\mathrm{S}}$ is the storage temperature, $T_{1}$ is the base storage temperature (below which after-ripening does not occur), and $t_{\mathrm{ar}}$ is the actual time in storage required for completion of after-ripening [the time required for $\Psi_{\mathrm{b}}(50)$ to change from its starting value to its final value; Bauer et al., 1998]. $T_{1}$ for B. tectorum seeds was assumed to be $0^{\circ} \mathrm{C}$, based on Bauer et al. (1998).

To expand TAR to include the effects of water potential, $\Psi_{b}(50)$ values calculated from the germination time course curves for each storage interval were regressed on thermal after-ripening time. A separate regression was performed for each storage water potential-storage temperature-incu- bation temperature combination. The resulting lines are described by the equation:

$$
\left.\Psi_{\mathrm{b}}(50)=m\left[\left(T_{\mathrm{s}}-T_{1}\right) t_{\mathrm{ar}}\right)\right]+b
$$

where $b$ is the initial value of $\Psi_{b}(50)$ before any thermal time is acquired, and the slope $(m)$ is the decrease in $\Psi_{\mathrm{b}}(50)$ per unit thermal time (i.e. $\mathrm{MPa} /{ }^{\circ}$ weeks). The values for these slopes (dormancy loss rates) were then plotted against storage water potential to describe the influence of water potential on the rate of after-ripening.

In performing regressions to determine afterripening rates, data obtained from storage from 0 to 240 degree-weeks were used. The decision to omit later values was based primarily on the observation that most after-ripening had occurred by this time, the response was nearly linear over this range, and a linear slope for each storage $\Psi$ was easier to fit into a hydrothermal after-ripening model. Seeds stored at $-40 \mathrm{MPa}$, which rapidly lost viability, were not included in further analyses.

\section{Simulation model development}

We used hourly seed-zone temperature and water potential values from the Point of the Mountain study site as driver variables for a simulation model to predict changes in $\Psi_{\mathrm{b}}(50)$ during after-ripening in the field. Initial and final $\Psi_{\mathrm{b}}(50)$ values from laboratory data were used as boundary values for starting and ending each simulation. The models were created using Microsoft Excel (Microsoft Works, Seattle, Washington, USA). They were similar in structure to our field simulation model for after-ripening as a function of thermal time (Bauer et al., 1998), but explicitly incorporated the effect of water potential on afterripening rate. For each hourly time step, the program calculated the expected decrement in $\Psi_{\mathrm{b}}(50)$, based on thermal time alone, as in the TAR model. If the measured water potential was $-150 \mathrm{MPa}$ or greater for that hour, the thermal time-based decrement was applied. If the measured water potential was $-375 \mathrm{MPa}$ or lower, a decrement of zero was applied (i.e. we assumed no after-ripening at or below this water potential threshold). If the measured water potential fell in the range from -375 to $-150 \mathrm{MPa}$, the decrement was calculated by subtracting the measured water potential from $-150 \mathrm{MPa}$, then dividing by $225 \mathrm{MPa}$ (the interval between -375 and $-150 \mathrm{MPa}$ ) to give a proportion that was then multiplied by the decrement based on thermal time alone, to correct for water potential (see Fig. 1). Hydrothermal time equations for the two seed collections were used to calculate observed $\Psi_{b}(50)$ values for seeds incubated at two temperatures following each weekly retrieval. Predicted $\Psi_{\mathrm{b}}(50)$ values after each time period in the 
field were then compared with observed values (i.e. obtained by incubating subsamples retrieved from the field). For each seed collection and incubation temperature, three simulations were performed: one based on TAR alone, one based on HTAR using water potential estimates from the Aquatel sensor, and one based on HTAR using estimates based on relative humidity measurements.

\section{Results}

\section{Hydrothermal time parameters}

All four seed populations were at least partially dormant when recently harvested (Table 1). Recently collected seeds incubated at $25^{\circ} \mathrm{C}$ had germination percentages that were $13-51 \%$ lower than seeds incubated at $15^{\circ} \mathrm{C}$, indicating that $\Psi_{b}(50)$ was higher at the warmer temperature before seeds after-ripened. For fully after-ripened seeds, $\Psi_{b}(50)$ was the same at both temperatures. The $\theta_{\mathrm{HT}}$ values for the Hobblecreek collection were similar both years; however, $\theta_{\mathrm{HT}}$ for the 1994 Whiterocks collection was nearly three times greater than for the 2002 Whiterocks collection. The low $\theta_{\mathrm{HT}}$ value for the Whiterocks 2002 collection was offset by a high $\Psi_{b}(50)$ value, which resulted in a similar germination rate in water for both collections. The $\sigma_{\Psi \mathrm{b}}$ values, which indicate germination uniformity, were nearly double for Hobblecreek

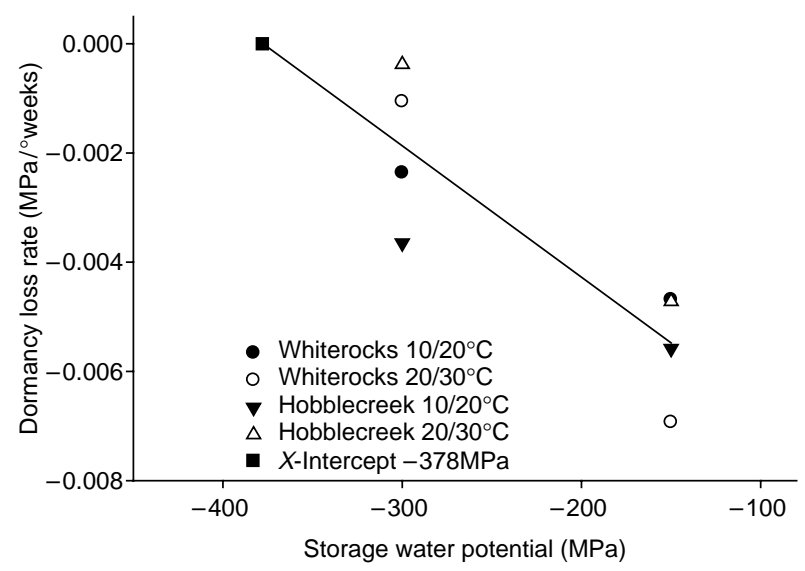

Figure 1. Dormancy loss rate for 1994 Bromus tectorum seeds, as indicated by changes in $\Psi_{\mathrm{b}}(50)$ per unit thermal time, plotted as a function of storage water potential. Regressions for the Whiterocks and Hobblecreek seed collections were determined (not shown); but because these slopes are not significantly different, the equation based on the common slope (shown on the figure) was used as the best estimate of dormancy loss rate. The $x$-intercept represents the extrapolated water potential estimate below which after-ripening does not take place. Dormancy loss rate $=0.0000241$ (Storage Water potential) $-0.0091 R^{2}=0.731$; D.F. $=6 ; P<0.01$. seeds collected in 2002 relative to the other three collections. $R^{2}$ values from probit regressions ranged from 0.84 to 0.91 , which were reasonably high and similar to those reported previously (Bauer et al., 1998).

\section{Hydrothermal after-ripening time model - 1994}

Seeds collected in 1994 and stored at - 150 MPa afterripened more quickly than those stored at $-300 \mathrm{MPa}$ (Fig. 1). Seeds stored at $-80 \mathrm{MPa}$ after-ripened at a rate essentially equivalent to the rate at $-150 \mathrm{MPa}$ (data not shown). Because of limited data (i.e. only two water potentials), we were forced to assume that the relationship between dormancy loss rate and water potential over the range -150 to $-300 \mathrm{MPa}$ was linear. In order to get the best estimate for the slope of this relationship, we combined data from both seed collections and both incubation temperatures into a single regression (Fig. 1). This regression also provides an extrapolated estimate of the water potential where after-ripening would be halted completely, namely the $x$-intercept, $-375 \mathrm{MPa}$.

\section{Field after-ripening simulation - 1994}

Field seed-zone water potential for the week of 7-14 July 1994 was representative of the hot, dry weather that summer (Fig. 2). Estimated soil seed-zone water potentials showed wide diurnal fluctuation between $c$. -150 and $-800 \mathrm{MPa}$ (Fig. 2). Measured seed-zone temperatures fluctuated between 12 and $57^{\circ} \mathrm{C}$ during this same time period. Water potential estimates based on Aquatel capacitance readings showed less overall fluctuation ( -150 to $-600 \mathrm{MPa})$ than did estimates based on relative humidity measurements $(-150$ to $-800 \mathrm{MPa}$ ), probably because the Aquatel sensor had reached its lower limit of detection. Both methods recorded a similar pattern of wide fluctuation in soil water potential values, and both consistently estimated very dry soil water conditions (almost never above $-150 \mathrm{MPa}$ ).

Thermal time (TAR) predictions of dormancy loss in the field during this exceptionally hot, dry summer were consistently the most rapid, nearly always faster than observed values for change in $\Psi_{b}(50)$ (Fig. 3). For the two HTAR models, the model based on soil water potential estimated from atmospheric humidity yielded the slowest predicted rate of after-ripening, and the model based on Aquatel sensor readings resulted in intermediate predictions. Three out of four observed plots of actual rates of change in $\Psi_{b}(50)$ fell at or between values predicted by one of the two HTAR approaches. For Whiterocks seeds incubated at $10 / 20^{\circ} \mathrm{C}$, the TAR model made the best prediction of dormancy loss, as indicated by decreased $\Psi_{\mathrm{b}}(50)$, especially for longer durations of after-ripening. 
Table 1. Germination percentages for recently harvested and fully after-ripened Bromus tectorum seeds, and hydrothermal time parameters for fully after-ripened seeds. Seeds were collected at two locations during June of 1994 and 2002

\begin{tabular}{|c|c|c|c|c|c|c|c|c|c|}
\hline & \multirow[b]{3}{*}{ Year* } & \multicolumn{4}{|c|}{ Germination (\%) } & \multirow[b]{3}{*}{$\theta_{\mathrm{HT}}\left(\mathrm{MPa}^{\circ} \mathrm{d}\right)$} & \multirow[b]{3}{*}{$\Psi_{\mathrm{b}}(50)(\mathrm{MPa})$} & \multirow[b]{3}{*}{$\sigma_{\Psi b}(\mathrm{MPa})$} & \multirow[b]{3}{*}{$\mathrm{R}^{2}$} \\
\hline & & \multicolumn{2}{|c|}{ At harvest } & \multicolumn{2}{|c|}{ After-ripened } & & & & \\
\hline & & $15^{\circ} \mathrm{C}$ & $25^{\circ} \mathrm{C}$ & $15^{\circ} \mathrm{C}$ & $25^{\circ} \mathrm{C}$ & & & & \\
\hline Whiterocks & 1994 & 69 & 56 & 97 & 95 & 42 & -1.22 & 0.31 & 0.89 \\
\hline Whiterocks & 2002 & 32 & 15 & 95 & 98 & 16 & -0.80 & 0.24 & 0.84 \\
\hline Hobblecreek & 1994 & 83 & 32 & 100 & 99 & 37 & -1.17 & 0.31 & 0.91 \\
\hline Hobblecreek & 2002 & 31 & 18 & 92 & 94 & 31 & -1.22 & 0.56 & 0.85 \\
\hline
\end{tabular}

${ }^{*}$ Incubation regimes in 1994 were actually $10 / 20^{\circ} \mathrm{C}$ and $15 / 25^{\circ} \mathrm{C}$ alternating $(12 \mathrm{~h} / 12 \mathrm{~h})$ temperature regimes; mean temperatures of the regime are reported above.

\section{Hydrothermal after-ripening time model - 2002}

As expected, 2002 seed collections stored at more negative water potentials equilibrated at lower water contents; water content decreased more or less exponentially with decreasing water potential for both collections (Fig. 4). Under the range of storage conditions included in this study, water contents

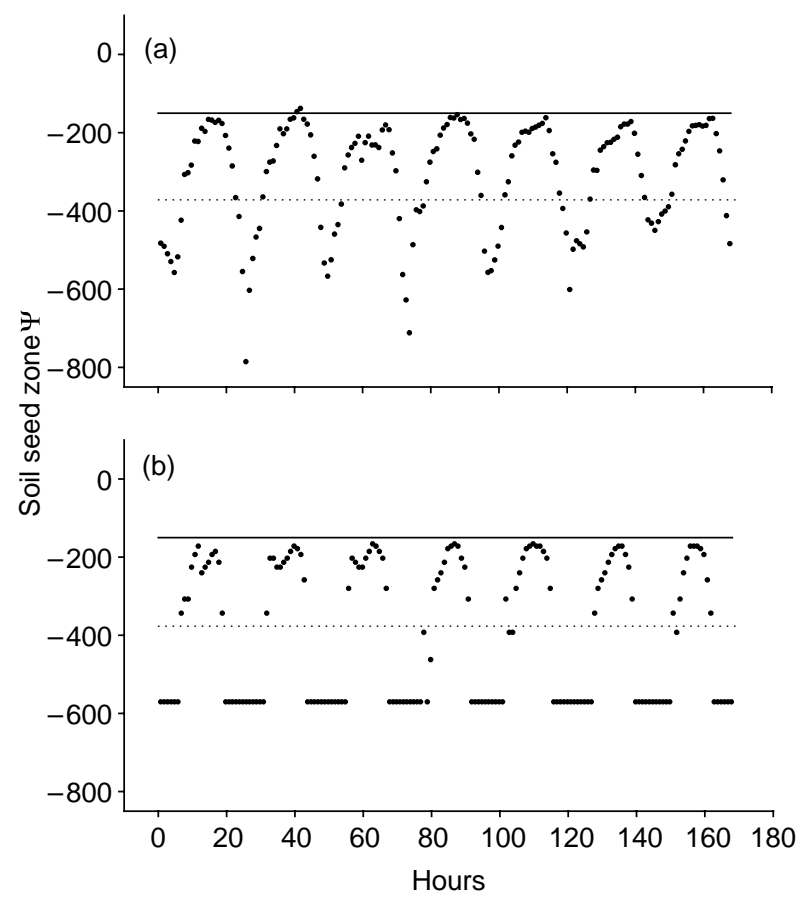

Figure 2. Field seed-zone water potential hourly estimates for the week of 7-14 July 1994 at Point of the Mountain, Utah, based on (a) soil capacitance readings and (b) measured atmospheric temperature and humidity, corrected for seed-zone temperature. The solid lines indicate the approximate water potential $(-150 \mathrm{MPa})$ below which afterripening is progressively reduced, while the dotted lines indicate the approximate water potential $(-375 \mathrm{MPa})$ where after-ripening is completely halted, based on the equation for 1994 seeds in Fig. 1. ranged from $0.02 \mathrm{~g} \mathrm{H}_{2} \mathrm{O}$ (g dry weight $)^{-1}$ at $-400 \mathrm{MPa}$ to $0.19 \mathrm{~g} \mathrm{H}_{2} \mathrm{O}$ (g dry weight $)^{-1}$ at $-40 \mathrm{MPa}$. Water contents at a given water potential were similar for the two seed collections, but were slightly higher at the lower storage temperature, as discussed by Walters (1998).

After-ripening, as indicated by decreasing $\Psi_{\mathrm{b}}(50)$ over time, was essentially prohibited at the most negative water potential ( $-400 \mathrm{MPa}$; Fig. 5). To verify that seeds had not been killed by this treatment, subsets of seeds stored at $-400 \mathrm{MPa}$ for 73 weeks were transferred to storage at 20 or $30^{\circ} \mathrm{C}$ and $-150 \mathrm{MPa}$ for 8 weeks. Seeds were then incubated at 15 or $25^{\circ} \mathrm{C}$ in water for $28 \mathrm{~d}$. Germination averaged $85 \%$ after $4 \mathrm{~d}$ and $91 \%$ after $28 \mathrm{~d}$ of incubation. In contrast, seeds stored at $-40 \mathrm{MPa}$ began to lose viability after only 8 weeks of storage, which led to spurious $\Psi_{\mathrm{b}}(50)$ values.

Over the water potential range from -350 to $-150 \mathrm{MPa}$, storage at progressively less negative water potentials resulted in correspondingly increased rates of after-ripening (Fig. 6). As in the 1994 data, no further acceleration of after-ripening occurred with storage at $-80 \mathrm{MPa}$. The influence of storage water potential on after-ripening rate was similar for both collections and incubation temperatures. Near $-400 \mathrm{MPa}$, or above $-150 \mathrm{MPa}$, there was little change in after-ripening rate as a function of storage water potential. Between -150 and $-350 \mathrm{MPa}$, the rate of after-ripening progressively increased (i.e. the dormancy loss rate became more negative, indicating a steeper rate of decrease in dormancy), as storage water potential became less negative. Therefore, the results of the 2002 experiments confirmed in broad outline the preliminary model developed from the 1994 data. Dormancy loss rates at -150 and $-300 \mathrm{MPa}$ were also similar in the two experiments (Figs 1,6), resulting in similar slopes as a function of water potential over this range.

At water potentials between -300 and $-80 \mathrm{MPa}$, after-ripening occurred more rapidly during the first 240 degree-weeks of storage (Fig. 5). Over this water potential range, the rate of after-ripening slowed as seeds neared completion of after-ripening. At 


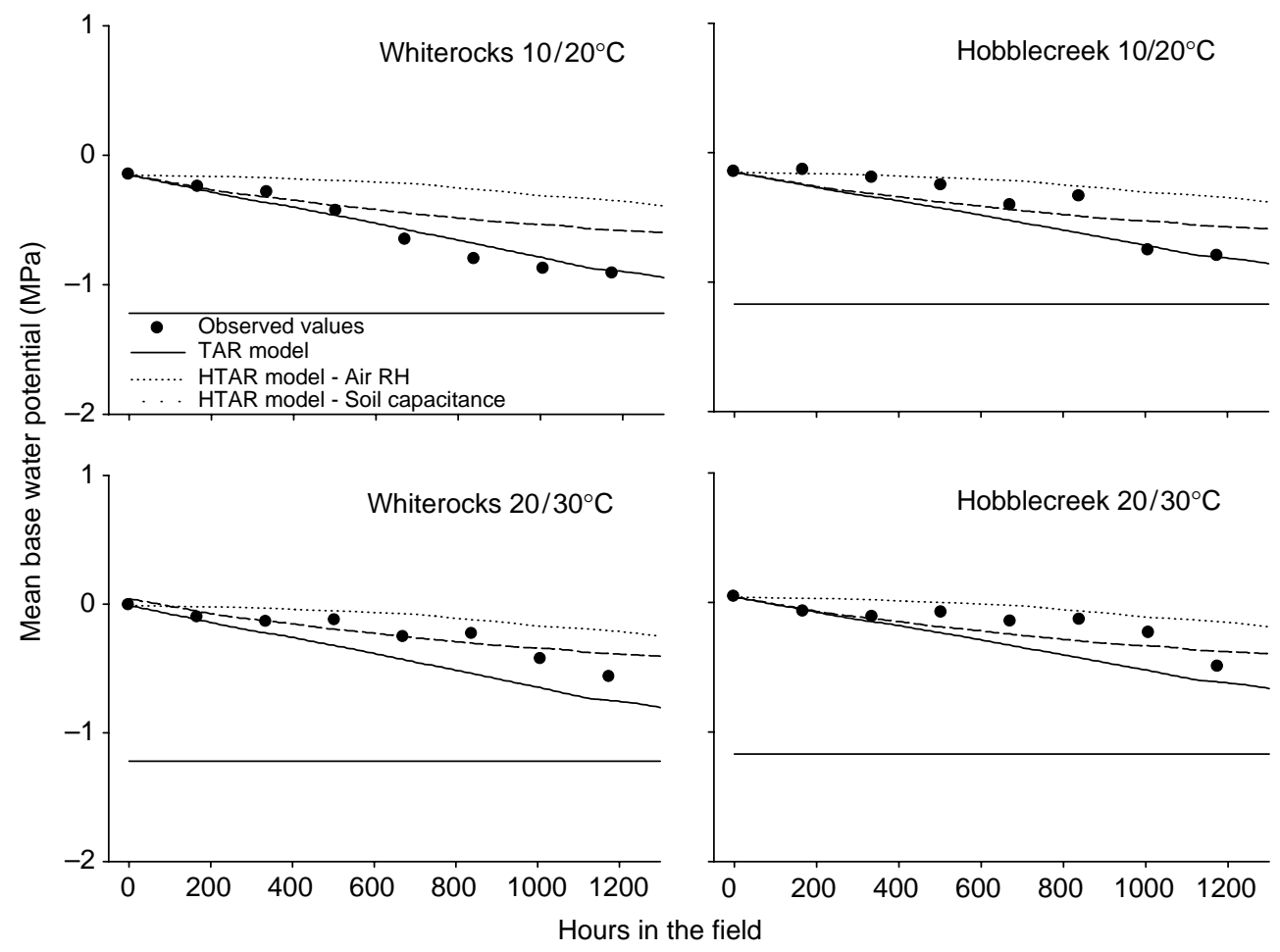

Figure 3. Predicted and observed changes in $\Psi_{\mathrm{b}}(50)$ during field after-ripening at Point of the Mountain, Utah for two 1994 collections of Bromus tectorum seeds. The horizontal line in each graph represents $\Psi_{\mathrm{b}}(50)$ for fully after-ripened seeds.

- $350 \mathrm{MPa}$, the decrease in $\Psi_{\mathrm{b}}(50)$ during storage was approximately linear.

Hobblecreek seeds reached a much lower final $\Psi_{\mathrm{b}}(50)$ value than did Whiterocks seeds (Table 1 ), but $\Psi_{b}(50)$ also decreased more rapidly during storage, especially at less negative water potentials. The slope of the regression line relating dormancy loss rate to water potential below $-150 \mathrm{MPa}$ was much steeper for the Hobblecreek collection (Figs 5, 6). The net result was that seeds from both 2002 collections required approximately the same amount of thermal time for completion of after-ripening at any given water potential.

\section{Discussion}

Physical and chemical reactions that occur in partially hydrated seeds appear to be limited by water potential thresholds, resulting in qualitative changes in the types of reactions that dominate at different levels of hydration (e.g. Vertucci and Farrant, 1995; Walters, 1998). It is interesting that Vertucci and Farrant's proposed critical moisture level of $-150 \mathrm{MPa}$, which these authors suggest as a discrete threshold for changes in metabolic activity between 'Hydration Level 1' and 'Hydration Level 2' (Fig. 1 in Vertucci and Farrant, 1995), appears to be identical to the threshold where after-ripening $B$. tectorum seeds can best be explained by TAR or HTAR. While our data do not provide a physiological explanation for why afterripening rate progressively declines below $-150 \mathrm{MPa}$, Vertucci and Farrant discuss Hydration Level 2 as containing water with glassy characteristics believed to have strong interactions with both polar surfaces of macromolecules and hydroxyl groups of solutes. In contrast, Hydration Level 1 is associated with water that binds to macromolecules as a structural component. As water is progressively removed from seed tissues, remaining water is increasingly bound more tightly to macromolecules, influencing the type of reactions allowed, as well as their kinetics (Walters, 1998). Mechanistic studies of low seed moisture to date, addressing almost exclusively questions related to seed ageing, have shown that loss of viability is promoted at very low moisture contents. We emphasize here, and discuss later, that the very low water potentials experienced by B. tectorum seeds in 1994 resulted in no apparent harm under field conditions.

We propose a conceptual framework to describe the influence of water potential on after-ripening in $B$. tectorum seeds (Fig. 7). The diagram includes four important ranges of seed water potential, with associated thresholds that determine which model (TAR versus HTAR versus no after-ripening) best 


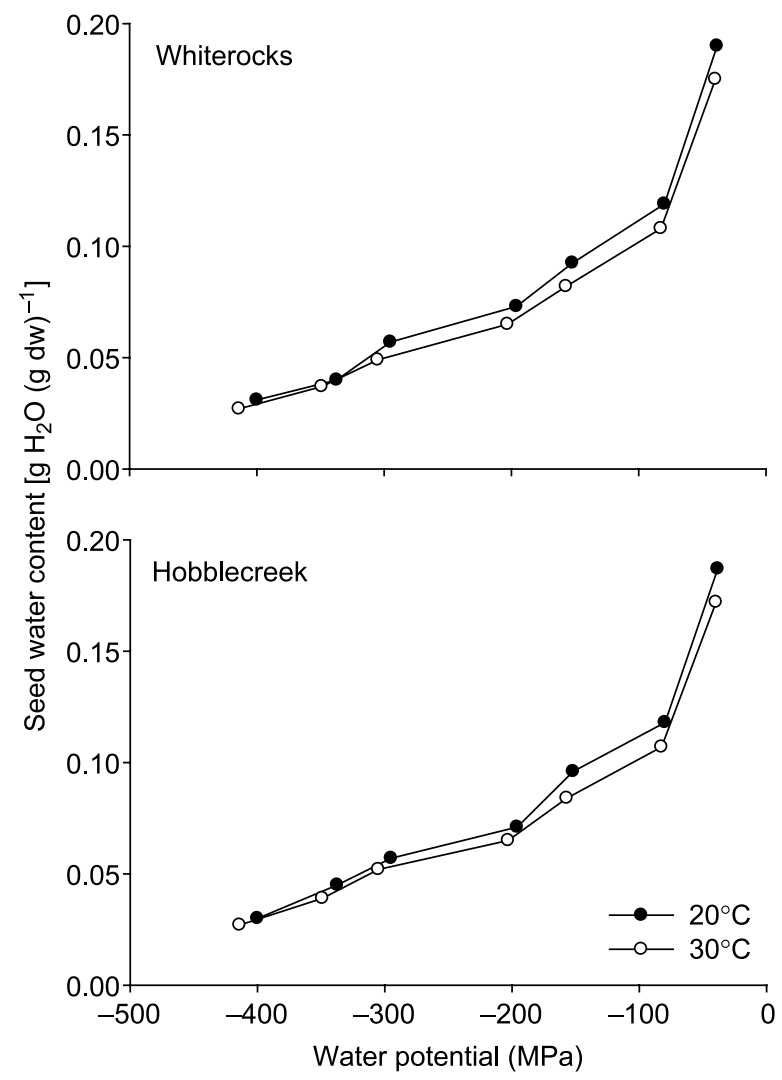

Figure 4. Water content for Whiterocks and Hobblecreek collections of Bromus tectorum seeds stored at 20 or $30^{\circ} \mathrm{C}$ after 8 weeks of storage over saturated salt solutions at a range of water potentials. Standard errors for each value are all smaller than symbols.

predicts dormancy loss. These ranges are as follows: (1) seeds stored below approximately $-375 \mathrm{MPa}$ do not after-ripen; (2) seeds stored between -375 and $-150 \mathrm{MPa}$ after-ripen as a function of both temperature and water potential, and dormancy loss can be explained by HTAR; (3) seeds stored at or above $-150 \mathrm{MPa}$ experience after-ripening as a linear function of temperature alone (TAR); and (4) seeds stored above $-40 \mathrm{MPa}$ are too wet for after-ripening to occur (they deteriorate, slowly progress toward germination or remain imbibed but dormant). In the widely fluctuating temperature and water potential environment that characterizes the soil seed-zone of semi-arid habitats, seeds likely cycle repeatedly through two or more of these ranges, depending on the specific water potential conditions both in and below the seed zone. The ability to successfully predict the rate of dormancy loss in the field suggests that seeds indeed lose dormancy progressively by integrating the effects of fluctuating temperature and water potential. Additional support for the HTAR model is provided by successful field predictions of after-ripening for seeds of the perennial bunchgrass Elymus elymoides (Bair, 2004).

Seeds stored at very low water contents have previously been reported to experience negligible after-ripening (Leopold et al., 1988; Foley, 1994; Steadman et al., 2003), but this finding with $B$. tectorum provides an ecologically relevant explanation for how seeds can be prevented from losing dormancy too rapidly. $B$. tectorum seeds mature in early summer, and typically experience weeks to months of hot, dry conditions that are not conducive to successful seedling establishment. If after-ripening were based solely upon thermal time, seeds would lose dormancy very quickly, and precocious germination (e.g. following summer thunderstorms) could result, reducing the probability of seedling survival. Seeds are prevented from losing dormancy at these times by an inhibited rate of after-ripening at very low water potentials, because high soil temperatures occur when the soil is also very dry.

While long-term storage at very low water potentials can damage seeds (e.g. Walters, 1998), we have not found this to be the case for wild plants adapted to desert and semi-desert habitats (e.g. Bauer et al., 1998; Meyer et al., 2000; Bair, 2004). Low water content probably does not affect viability of seeds in the field, possibly because fluctuating soil water potentials either prevent the accumulation of reactions that favour seed ageing and subsequent loss of viability, or they allow for repair processes to occur when seeds temporarily become hydrated. Given the high summer temperatures and low humidity in desert and semi-desert seed regions, the ability to survive as seeds under these conditions would clearly be advantageous.

The second range of storage water potentials proposed in Fig. 7 predicts dormancy loss according to a hydrothermal after-ripening time model. Model development often requires many simplifying assumptions. One decision made earlier in the development of TAR (Bauer et al., 1998) was to ignore the influence of soil water potential. The assumption was based on the fact that soil water potential values averaged $>-150 \mathrm{MPa}$ during the year of study (1995), and TAR alone was a good predictor of actual after-ripening rates. However, in 1994, a particularly dry year, the TAR model overestimated the rate of after-ripening for field data. By including the combined influence of seedzone water potential and temperature on afterripening rate, the HTAR model generally predicted dormancy loss more accurately than TAR. We do not have an explanation for the single exception to superiority of the HTAR over the TAR model (Whiterocks seeds tested at $10 / 20^{\circ} \mathrm{C}$ ). Because the HTAR model also produced better results than did 

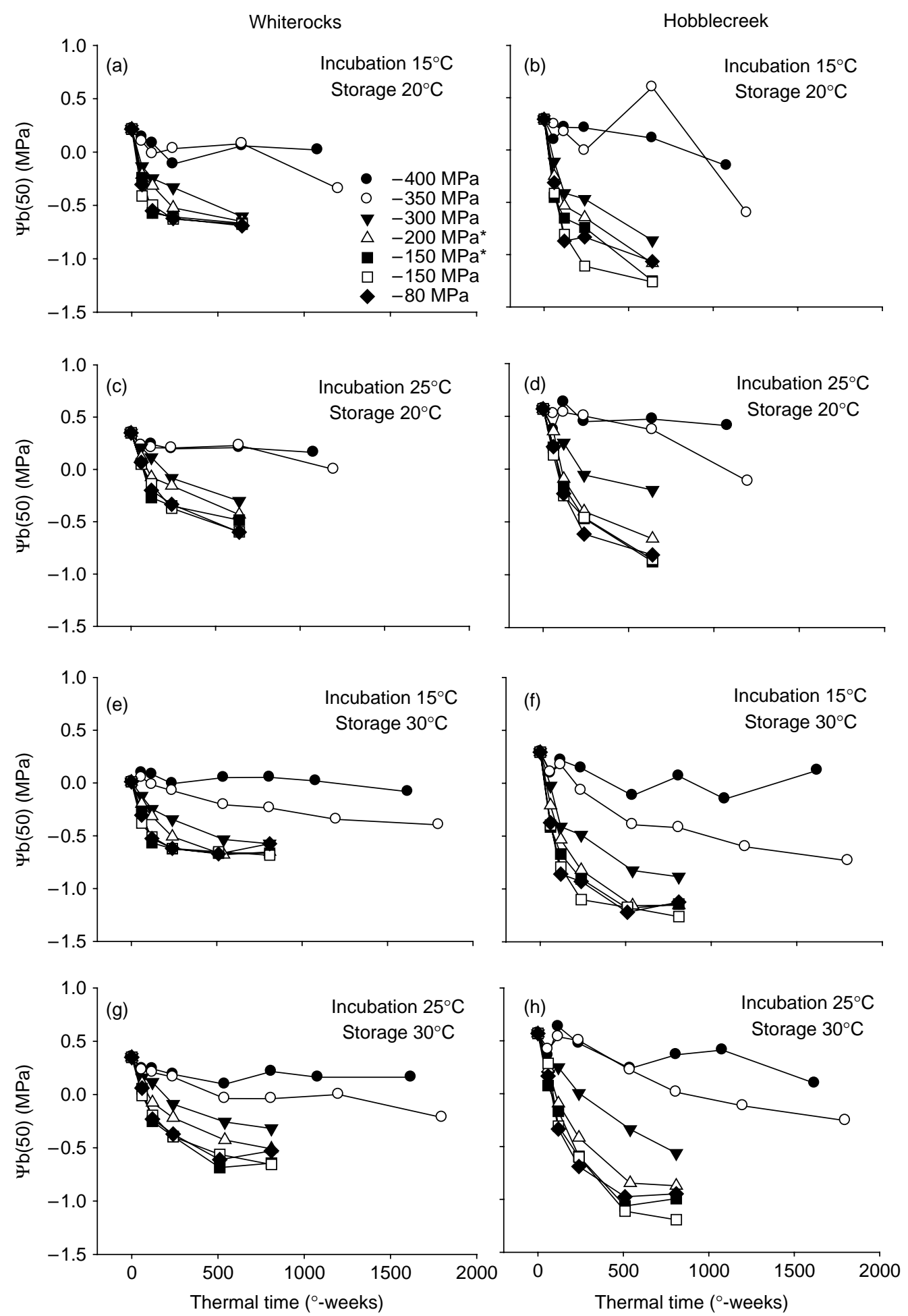

Figure 5. Dormancy status as indicated by $\Psi_{\mathrm{b}}(50)$ for 2002-collected Bromus tectorum seeds from Whiterocks and Hobblecreek, as influenced by storage water potential, storage temperature, storage duration and incubation temperature. Water potentials marked with an asterisk indicate seeds were equilibrated above glycerol solutions; all other water potentials were achieved above saturated salt solutions. Values for $-40 \mathrm{MPa}$ are not included because seeds rapidly lost viability in this treatment, resulting in spurious $\Psi_{\mathrm{b}}(50)$ values. 

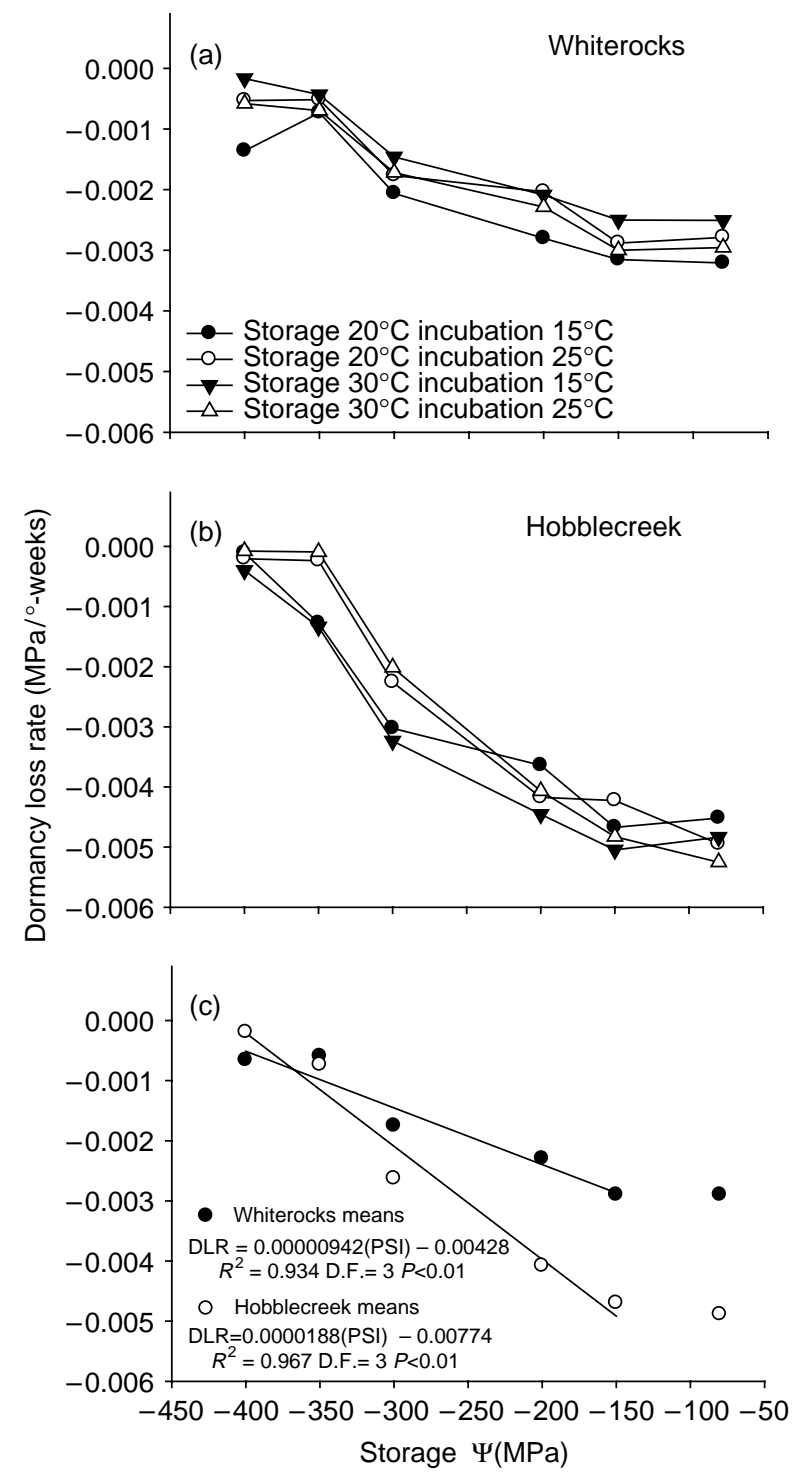

Figure 6. Dormancy loss rate [change in $\Psi_{\mathrm{b}}(50)$ per unit thermal time] for 2002-collected Bromus tectorum seeds stored at $20^{\circ} \mathrm{C}$ or $30^{\circ} \mathrm{C}$ and incubated at $15^{\circ} \mathrm{C}$ or $25^{\circ} \mathrm{C}$, plotted as a function of storage water potential: (a) Whiterocks and (b) Hobblecreek. Values for 0 to 240 degree-weeks of storage from Fig. 5 were used in regressions to obtain the slope of dormancy loss for each storage temperature-storage water potential-incubation temperature combination. (c) Dormancy loss rates for each seed population were averaged across storage temperature and incubation temperature at each storage water potential; mean dormancy loss rates were then regressed on storage water potential over the range of -150 to $-400 \mathrm{MPa}$. The mean dormancy loss rate at $-80 \mathrm{MPa}$ is shown to demonstrate the lack of change as a function of water potential at water potentials $>-150 \mathrm{MPa}$. The $x$-intercept predicted for Hobblecreek is $-412 \mathrm{MPa}$ and for Whiterocks is $-454 \mathrm{MPa}$.
TAR for seeds of E. elymoides (two populations) included in this same experiment (Bair, 2004), the HTAR model should consistently provide a better overall model for use in very dry soils.

We believe that simulation modelling of dormancy loss for B. tectorum is ultimately limited by the ability to estimate seed water potentials accurately in the field. When B. tectorum seeds were alternated between -150 and $-300 \mathrm{MPa}$ on a diurnal basis, seed water content on average was much closer to the equilibrium value for -150 than for $-300 \mathrm{MPa}$ (P. Allen, unpublished data). This suggests that seed water potential does not necessarily reflect soil water potential values under wide diurnal fluctuations. In addition, studies with barley (Hordeum vulgare) suggest that water moves preferentially to the embryo from other seed tissues when previously imbibed seeds dry (Allen et al., 2000). Thus, whole-seed measurements or estimates of water status may be unreliable under a diurnal cycle characterized by wide fluctuations in temperature and water potential.

The after-ripening rate of seeds stored between -80 and $-300 \mathrm{MPa}$ was approximately linear initially, followed by a progressively slower rate that often led to an overall curvilinear response. In some storage treatments, seeds failed to complete dormancy loss, which is partially a result of the experiment being terminated before a fully afterripened state was attained. Seeds stored at -350 , -300 and $-200 \mathrm{MPa}$ after-ripened more slowly with time, and even began to level off at less negative $\Psi_{b}(50)$ values. If the underlying mechanisms associated with after-ripening include complex processes involving multiple reactions that occur at different rates, it is possible that some reactions might be slowed or prevented at water potentials above $-400 \mathrm{MPa}$ (Vertucci and Farrant, 1995). In addition, if a primary reaction controls the rate of initial after-ripening and a secondary reaction (i.e. with a slower rate) takes longer to complete, the combined result would be a curvilinear response. Gianinetti and Cohn (unpublished data, 2005) used a $\log$ transformation to linearize the negative curvilinear relationship between $\Psi_{\mathrm{b}}(50)$ and thermal time, rather than just using the linear initial phase, to better describe dormancy loss in red rice seeds. However, for the purpose of predicting dormancy loss in the field, using the linear initial slope appeared to be sufficiently accurate, and simplified model development.

When water potentials were above $-150 \mathrm{MPa}$ and the soil was still relatively dry (the third region identified in Fig. 7), TAR was sufficient to predict after-ripening (Bauer et al., 1998). For the TAR portion of the model, we assumed that the relationship between storage temperature and after-ripening rate 


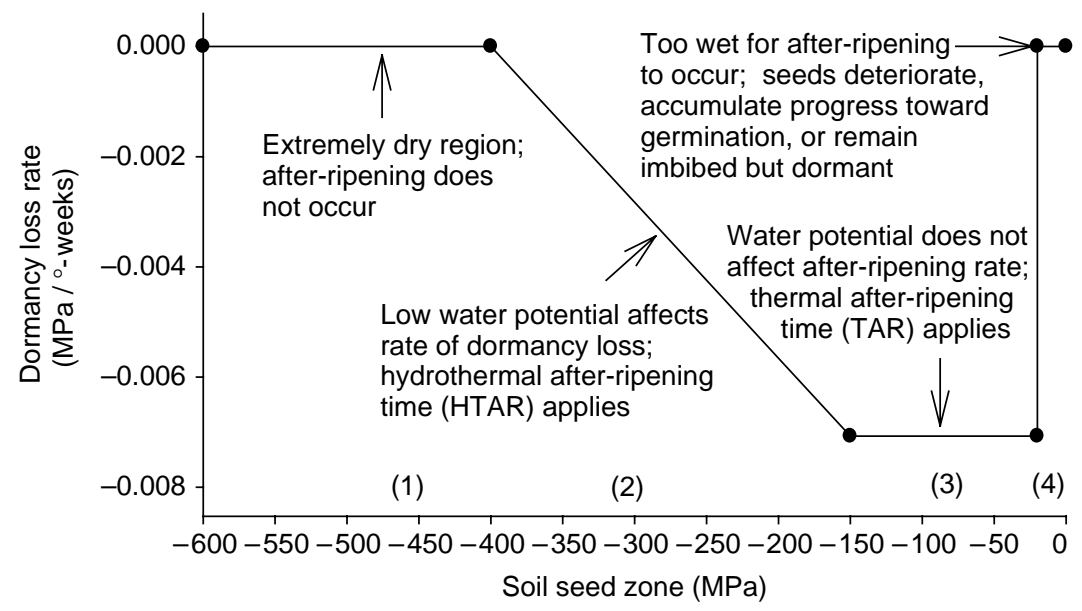

Figure 7. Conceptual diagram proposing how storage water potential influences after-ripening in Bromus tectorum seeds. The four regions and the associated threshold water potentials are discussed in the text.

was the same for both incubation temperatures. This implies that after-ripening rates would be approximately equal for all incubation temperatures, with only initial and possibly final $\Psi_{\mathrm{b}}(50)$ values varying with incubation temperature (Meyer et al., 2000). The 2002 data set generally supported this assumption. Failure to include this simplifying assumption would greatly complicate the simulation model, because in prediction of field germination based on dormancy status, incubation temperature is also a continuous and fluctuating variable, not a defined laboratory regime. An adequate test of the assumption that afterripening rates are uniform across incubation temperatures would require multiple incubation temperature regimes that were not included in this study.

The fourth region in our conceptual after-ripening model (Fig. 7) is too wet for after-ripening to occur. At these water potentials, seeds deteriorate, accumulate progress toward germination or remain imbibed but dormant. In any case, storing seeds at constant water potentials above $-40 \mathrm{MPa}$, but below the threshold for radicle emergence, creates experimental difficulties that prevent meaningful interpretation of afterripening results.

Results from $-40 \mathrm{MPa}$ storage treatments were difficult to interpret due to rapid loss of viability. As seeds age they lose vigour, take longer to germinate (Ellis and Roberts, 1980, 1981) and eventually lose the ability to germinate (Walters, 1998). Extended exposure to water potentials near $-40 \mathrm{MPa}$ does not typically occur in semi-arid environments. Fluctuating temperatures, evaporation of water from the soil and precipitation all contribute to widely fluctuating water potential cycles. Although B. tectorum seeds regularly experienced water potentials above $-40 \mathrm{MPa}$ in the field during the summer of 1995 (Bauer et al., 1998), it was generally just a few hours before seeds were either close to $0 \mathrm{MPa}$ or much drier. As with seeds frequently exposed to very dry soil conditions, seeds of $B$. tectorum that encountered moderately moist soil conditions did not lose viability in the field.

We propose a model that defines four ranges of water potential that influence the rate of after-ripening. The first range involves seeds that are experiencing very dry soil water potential conditions, where negligible afterripening occurs. In the intermediate range, decreasing water potentials progressively inhibit after-ripening rate. The third range can be explained by thermal afterripening time alone, and the wettest range fails to promote after-ripening (i.e. 'dry after-ripening' does not occur in wet seeds). Incorporating water potential into models that predict dormancy loss through afterripening provides more accurate field predictions of dormancy loss than TAR alone. The model is consistent with both empirical and theoretical literature on the physiology of incompletely hydrated seeds (Vertucci and Farrant, 1995; Walters, 1998), although this literature is directed toward answering questions other than dormancy loss per se. The model has potential for making better predictions of dormancy loss under the widely fluctuating soil water potential conditions that occur in the field. Linking the hydrothermal afterripening time with hydrothermal time for germination will be an important step in creating a combined model to account for both dormancy and germination under fluctuating water potential and temperature conditions.

\section{Acknowledgements}

Technical assistance for this project was provided by Brian Anderson, Jennifer Baker-Xanthos, Julie Beckstead, Heather Beecher, Eric Castle, Maren Bauer, Becky Peterson and Amanda Silvester. 


\section{References}

Allen, P. (2003) When and how many? Hydrothermal models and the prediction of seed germination. New Phytologist 158, 1-3.

Allen, P.S., Thorne, E.T., Gardner, J.S. and White, D.B. (2000) Is the barley endosperm a water reservoir for the embryo when germinating seeds are dried? International Journal of Plant Science 161, 195-201.

Alvarado, V. and Bradford, K.J. (2002) A hydrothermal time model explains the cardinal temperatures for seed germination. Plant, Cell and Environment 25, 1061-1069.

Bair, N.B. (2004) A hydrothermal after-ripening time model of seed dormancy loss in Bromus tectorum. MS Thesis, Brigham Young University, Provo, Utah.

Bauer, M.C., Meyer, S.E. and Allen, P.S. (1998) A simulation model to predict seed dormancy loss in the field for Bromus tectorum L. Journal of Experimental Botany 49, 1235-1244.

Bradford, K.J. (1990) A water relations analysis of seed germination rates. Plant Physiology 94, 840-849.

Bradford, K.J. (1995) Water relations in seed germination. pp. 351-396 in Kigel, J.; Galili, G. (Eds) Seed development and germination. New York, Marcel Dekker.

Bradford, K.J. (2002) Applications of hydrothermal time to quantifying and modeling seed germination and dormancy. Weed Science 50, 248-260.

Bradford, K.J. (2005) Threshold models applied to seed germination ecology. New Phytologist 165, 338-341.

Christensen, M., Meyer, S.E. and Allen, P.S. (1996) A hydrothermal time model of seed after-ripening in Bromus tectorum L. Seed Science Research 6, 155-163.

Copeland, L.O. and McDonald, M.B. (2001) Principles of seed science and technology (4th edition). Boston, Kluwer Academic.

Ellis, R.H. and Roberts, E.H. (1980) Towards a rational basis for testing seed quality. pp. 605-635 in Hebblethwaite, P.B. (Ed.) Seed production. London, Butterworth and Co.

Ellis, R.H. and Roberts, E.H. (1981) The quantification of aging and survival in orthodox seeds. Seed Science and Technology 9, 373-409.

Foley, M.E. (1994) Temperature and water status of seed affect afterripening in wild oat (Avena fatua). Weed Science $42,200-204$.

Forney, C.F. and Brandl, D.G. (1992) Control of humidity in small controlled-environment chambers using glycerolwater solutions. HortTechnology 2, 52-54.

Gummerson, R.J. (1986) The effect of constant temperatures and osmotic potentials on the germination of sugar beet. Journal of Experimental Botany 37, 729-741.

Hanks, R.J. (1992) Applied soil physics. New York, SpringerVerlag.

Hardegree, S.P., Van Vactor, S.S., Pierson, F.B. and Palmquist, D.E. (1999) Predicting variable-temperature response of non-dormant seeds from constant-temperature germination data. Journal of Range Management 52, $83-91$.

Kebreab, E. and Murdoch, A.J. (1999) Modelling the effects of water stress and temperature on germination rate of Orobanche aegyptiaca seeds. Journal of Experimental Botany 50, 655-664
Leopold, A.C. and Vertucci, C.W. (1989) Moisture as a regulator of physiological reaction in seeds. pp. 51-67 in Stanwood, P.C.; McDonald, M.B. (Eds) Seed moisture. Special publication 14. Madison, Wisconsin, Crop Science Society of America.

Leopold, A.C., Glenister, R. and Cohn, M.A. (1988) Relationship between water content and afterripening in red rice. Physiologia Plantarum 74, 659-662.

Mack, R.N. (1981) Invasion of Bromus tectorum L. into Western North America: An ecological chronicle. AgroEcosystems 7, 145-165.

Meyer, S.E., Debaene-Gill, S.B. and Allen, P.S. (2000) Using hydrothermal time concepts to model seed germination response to temperature, dormancy loss, and priming effects in Elymus elymoides. Seed Science Research 10, 213-223.

Michel, B.E. (1983) Evaluation of the water potentials of solutions of polyethylene glycol 8000 both in the absence and presence of other solutes. Plant Physiology 72, 66-70.

Phelps, K. and Finch-Savage, W.E. (1997) A statistical perspective on threshold type germination models. pp. 361-368 in Ellis, R.H.; Black, M.; Murdoch, A.J.; Hong, T.D. (Eds) Basic and applied aspects of seed biology. Dordrecht, Kluwer Academic.

Rowse, H.R. and Finch-Savage, W.E. (2003) Hydrothermal threshold models can describe the germination response of carrot (Daucus carota) and onion (Allium cepa) seed populations across both sub- and supra-optimal temperatures. New Phytologist 158, 101-108.

Schneider, M.J.T. and Schneider, A.S. (1972) Water in biological membranes: adsorption isotherms and circular dichroism as a function of hydration. Journal of Membrane Biology 9, 127-140.

Shrestha, A., Roman, E.S., Thomas, A.G. and Swanton, C.J. (1999) Modeling germination and shoot-radicle elongation of Ambrosia artemisiifolia. Weed Science 47, 557-562.

Steadman, K.J., Crawford, A.D. and Gallagher, R.S. (2003) Dormancy release in Lolium rigidum seeds is a function of thermal after-ripening time and seed water content. Functional Plant Biology 30, 345-352.

Vertucci, C.W. and Farrant, J.M. (1995) Acquisition and loss of desiccation tolerance. pp. 237-271 in Kigel, J.; Galili, G. (Eds) Seed development and germination. New York, Marcel Deckker.

Walters, C. (1998) Understanding the mechanisms and kinetics of seed aging. Seed Science Research 8, 223-244.

Walters, C., Pammenter, N.W., Berjak, P. and Crane, J. (2001) Desiccation damage, accelerated ageing and respiration in desiccation tolerant and sensitive seeds. Seed Science Research 11, 135-148.

Winston, P.W. and Bates, D.H. (1960) Saturated solutions for the control of humidity in biological research. Ecology 41, 232-237.

Received 12 July 2005

accepted after revision 15 November 2005

(c) CAB International 2006 